\title{
Construction and Optimization of Logistics Supply Chain Model based on Fresh Agricultural Products
}

\author{
Junde $\operatorname{Han}^{1,}$ a \\ ${ }^{1}$ Tianjin Agricultural College, Tianjin, 300384 \\ a email
}

Keywords: Fresh Agricultural Products; Logistics; Supply Chain; Construction Model; Optimization

\begin{abstract}
With the development of Chinese economy, the agricultural production structure has also been greatly adjusted. The continuous progress of agricultural technology has led to the steady and healthy growth of the consumption of fresh products in China. In order to better meet the needs of the people, A time to the hands of consumers, you need to establish a sound science of fresh agricultural products supply model, according to statistics in China each year because of some factors such as logistics loss of fresh agricultural products to $40 \%$, so in order to solve the fresh agricultural products logistics process To bring the loss of this serious problem, you need to use modern logistics concepts and technologies to meet the needs of the market to build a logistics supply model. This paper analyzes the present situation of the supply chain of raw agricultural products in China, and analyzes the market supply situation of our country to explore the more optimized supply chain of raw agricultural products.
\end{abstract}

\section{Introduction}

With the construction of Chinese information society, consumers in the fresh agricultural product purchase model presents a variety of state, the application of e-commerce and agricultural products to improve the level of logistics, making people in the consumption of these products at the same time, security awareness has gradually increased The With the change of agricultural structure in China, some of the cultivation and production of fresh agricultural products are becoming more and more standardized, but the development of agricultural product supply chain can not adapt to the development of the times. Nowadays, the market demand is more and more open, the market environment It is necessary to innovate and reform the supply chain model of fresh agricultural products, and establish an efficient, fast and perfect mode of supply of modern fresh agricultural products. It is necessary to innovate and reform the fresh agricultural products supply chain. , To promote the efficient and efficient circulation of agricultural products, is the focus of the current study.

\section{The Concept of Raw Agricultural Supply Chain}

Fresh agricultural products supply chain refers to the fresh agricultural products for the packaging, transportation, warehousing and other logistics object supply chain system, in addition to fresh agricultural products itself, but also the supply of fresh agricultural products, circulation processing enterprises, distributors and consumers Etc. [1]. Raw producers of raw agricultural products are the beginning of the supply chain, and then through a variety of distribution, processing and retail to reach the hands of consumers in some of the links constitute a fresh agricultural supply chain. It can also be said that in order to better meet the consumer as a goal through the organized and planned logistics activities, so that fresh produce from the production to the final processing to the consumer some of the process known as the fresh agricultural supply chain. The characteristics of fresh agricultural products are mainly manifested as fresh, ready-to-eat and difficult to store, so in the logistics storage, transportation and distribution process in order to better keep the product fresh, you need the logistics supply chain facilities and equipment are the same With a good freshness, the exchange of information flexible, high logistics efficiency, but also the basic requirements of raw agricultural supply chain. 


\section{Characteristics of Fresh Agricultural Products}

For the cultivation and production of fresh agricultural products, the seasonal characteristics of its production are obvious, such as some fruit, vegetable production has a fixed season. For some livestock and poultry, aquatic products are relatively scattered farming, are some independent farmers for farming. Compared with the developed countries, the production method is more flexible, resulting in the difficulty of increasing the logistics of fresh agricultural products [2].

In addition, timeliness and freshness are characterized by the circulation of fresh produce. In order to make fresh agricultural products as soon as possible to reach the hands of consumers, need to continue to enhance the logistics, handling, distribution technology to enhance the quality of logistics and transport. Perishable characteristics, it is required to change the traditional mode of transport, to enhance the transport process of cold storage and low temperature. For some fresh aquatic products are required to increase the feeding facilities, as far as possible in the transport process to reduce the loss of fresh agricultural products.

Demand characteristics directly affect the fresh agricultural products logistics, which is reflected in two aspects: First, urban residents for the increase in the demand for fresh agricultural products. Due to the improvement of living standards, the demand for fresh agricultural products has increased in recent years, and the urban population is concentrated. Therefore, the demand is large, and a better distribution system needs to be established to meet the daily needs of people. With the improvement of people's living standards, people's demand for fresh agricultural products in addition to the increase in the quality of fresh agricultural products have a high demand, including the fresh produce for the appearance, taste, freshness, packaging As well as fresh agricultural products sales link of the storage environment and so on have a very high demand. The change in the concept of fresh agricultural demand also determines the change of its logistics mode and the improvement of supply chain capacity.

Sales of fresh agricultural products on the one hand the performance of scattered farmers, on the other hand is an organized market, the convergence between the two is the main problem, the current market is mainly dependent on farmers or small traders to the wholesale market , Wholesalers and then vegetables from the origin of the wholesale market to the distribution of the market, and then through the city distribution center to the market and supermarket [4]. For fresh agricultural products do not need deep processing, are generally in the form of primary products after sorting, packaging, cleaning finishing, weighing, testing the sale after the immune, so for the fresh product supply chain, there is no link in the manufacturer.

\section{Current Situation of Fresh Agricultural Products Supply Chain}

With the rapid development of Chinese economy in recent years, Chinese logistics economy has also been greatly improved, especially the level of agricultural products significantly improved, but compared to other developed countries still exist this gap. Mainly in the process of transport of fresh agricultural products in the high rate of loss, reaching $20 \%$ to $30 \%$, while the loss of developed countries is only $1.7 \%$ to $5 \%$, the gap can be seen from this [5]. The other is Chinese fresh agricultural products to farmers market transactions, and developed countries to supermarket-based circulation. At the same time in the process of transportation and storage of fresh agricultural products, Chinese fresh agricultural transport in the process of refrigerated transport rate of only $15 \%$ to $20 \%$, while the cold storage of fresh agricultural products wholesale market accounted for only $38.56 \%$, so for the fresh agricultural products supply chain problems exist mainly for the following aspects:

First of all, for the logistics costs of fresh agricultural products, the logistics management process of human and material resources are an important part of the cost of logistics, as with the development of society, human resources costs increase, making the logistics costs. In addition, in addition to what we call the fresh agricultural products on the transport, storage of higher requirements, but also because of the spread of fresh agricultural products, resulting in drivers because the route is not familiar with the cost of transport process increased. Combined with the 
above reasons, making fresh agricultural products in the entire logistics link costs significantly increased.

Followed by the lack of safety of fresh agricultural products transport system, a lot of fresh agricultural products in the transport of food safety is still a great hidden danger, so in order to better ensure the quantity and safety of transport, we must establish a sound logistics system, Social responsibility of the logistics system. At the same time in order to meet the market demand for green products, must be in the management and service, product quality and type of common development, the establishment of a distinctive agricultural market of fresh agricultural products.

In addition to fresh agricultural products, in order to better ensure its quality, in the transport process of cold storage is the primary condition, but for Chinese cold chain logistics is relatively slow development, still no mature cold chain system, which also Resulting in a lot of fresh agricultural products in the circulation process of greater wear and tear.

In addition, although some places with the market environment changes and people's spending power, fresh agricultural products chain has gradually formed, but more people still choose to go to agricultural products market, according to statistics, Chinese fresh agricultural products in the Farmers market liquidity as high as $70 \%$ or more. Although the fresh agricultural products in the farmers market flow larger, but many places the construction of agricultural products market is relatively backward, the market function is relatively simple, the infrastructure is not perfect, the market management level is low, organization chaos, there is no adaptation of fresh agricultural products market mechanism, Resulting in the entire fresh agricultural products logistics efficiency is low, serious loss.

Finally, for the current fresh agricultural products, the level of commercialization and standardization is low, although now gradually emerged a large number of agricultural production base, but the standardization of fresh agricultural products, the degree of commercialization is low, and its conversion rate of only $30 \%$, The proportion of finished food is less, and most of the circulation market is too small, scattered business, standardization is not high, many businesses in the business lack of brand awareness, making the overall fresh agricultural competitiveness is weak.

\section{Construction and Optimization of Logistics Supply Chain Model for Fresh Agricultural Products}

For fresh agricultural products, its logistics system is efficient, to a large extent determine the quality of its products. So the establishment of a sound logistics system can be fast to the hands of consumers to the hands of consumers, on the one hand to reduce the cost of intermediate links, on the other hand also reduce the fresh agricultural products in the logistics process of decay possible to ensure that consumers Edible freshness, improve the quality of fresh agricultural products.

Fresh agricultural products logistics system can be divided into product demand, product production and product quality testing, these three aspects to ensure that the product flow through the security, so in order to better promote the development of logistics chain, we must first ensure that The entire logistics chain system of product quality testing security, consumers can be more at ease with the consumption of these products, and thus the steady growth of demand for fresh agricultural products.

A good job of fresh agricultural products logistics related business credit evaluation. In order to better enable the safe and efficient operation of the raw agricultural supply chain system, we can construct the credit rating system of the agricultural logistics enterprises [7]. Based on the quality and price of agricultural products, the efficiency of logistics functional modules as the fulcrum, with information sharing, so that enterprises involved in agricultural logistics can consciously participate in the construction of food safety system, and strive to make this evaluation system can cover to Fresh agricultural products supply chain for every business.

In the agricultural industrialization in the establishment of leading enterprises to production and processing enterprises to dominate the supply pattern of fresh agricultural products, the current situation in China is more in line with the development of agriculture, the main task of the model is the production and processing enterprises of agricultural products responsible for Agricultural 
products to track the various aspects of logistics control. In this model, all enterprises involved in the circulation of fresh agricultural products can share the information in all aspects of product circulation, minimize the circulation, while ensuring the quality of products in the circulation process, can make the whole fresh agricultural products more perfect.

In the investigation of Chinese agricultural trade found that the main agricultural products circulation and transactions or to the wholesale market-based, which is Chinese agricultural development of a major advantage, you can save a lot of transaction costs, while the product can be a reasonable allocation [8], the market demand is more stable. Wholesale market-oriented logistics supply chain formation mainly due to the core of the wholesale market and the main tasks of the market by the large-scale agricultural market operators to bear the wholesale market, the continuous operation of the deepening of the modern management of continuous improvement and efficient operation and management in the logistics Supply chain has played an important role, has formed a production, processing, storage, sales, distribution as one model. In addition, with the development of market information, logistics has gradually owned a modern information management platform, so in order to make healthy agricultural products in the wholesale market healthy and orderly transactions, we must rely on modern management technology, Series of sorting, packaging and so on need to have a computer and modern information technology as a support, establish and improve the unified wholesale retailers, manufacturers and other integrated systems to ensure that the entire supply chain to achieve better information sharing.

Some sent to the country's fresh agricultural products business model is mostly supermarket chain-based, can be very convenient to market demand for centralized and unified, improve market performance. China has a lot of cities have formed a more mature supermarket system, fresh agricultural products has become a necessary commodity, many people because of the pace of life to speed up, do not want to bargain to the farmers market, so the supermarket chain has become the main place to buy their goods [9]. In addition, the supermarket chain has a unified distribution and transportation, in the fresh agricultural products logistics and transport links, directly from the production base of the procurement of goods, reducing a lot of circulation, to ensure the quality of the product, for the current consumer is more able to meet their needs.

\section{Conclusion}

Fresh agricultural products are indispensable in our lives, related to all aspects of our lives, so the establishment of a more comprehensive logistics supply chain model and the existing management measures to optimize, can greatly reduce the middle of the circulation of fresh agricultural products to ensure that the product Fresh, so that consumers buy convenience, food more at ease. In the rapid development of information society today, from the production, processing, sales of information to do the unity of information, can ensure the safety of the production process and reduce the fresh agricultural products from the field to the supermarket to the table logistics costs and thus improve The operation efficiency of fresh agricultural products logistics, improve the service level of fresh agricultural products logistics enterprises.

\section{References}

[1] Li Dong. Analysis on the Evolving Path and Motivation of Fresh Agricultural Products Logistics Supply Chain Model [J]. Commercial Economics Research, 2016, (06): 86-87.

[2] Wang Xuhui, Zhang Qilin. E-commerce to break the inherent mechanism of the plight of the circulation of fresh agricultural products -based on the days of cat fresh and Tuotuo workers of the two cases of comparative study [J]. China Soft Science, 2016, (02): 39-55.

[3] He Guojie. Shandong fresh agricultural product logistics supply chain model construction and optimization [J]. Logistics Technology, 2014, (17): 341-343.

[4] Zhao Zhitian, Yang Jianzheng. Structural Framework, Inspection and Development Strategy of Agricultural Product Logistics under Electric Merchant Environment-Data from Lishui, 
Zhejiang [J]. China Circulation Economics, 2014, (06): 108-113.

[5] Sun Mei, Zhao Yuechun, Li Guangshui. Construction of the Supply Chain of Fresh Agricultural Products with Large Logistics Center [J]. Jiangsu Agricultural Sciences, 2014, (02): 366-368.

[6] Fan Cunjun. The scale economy and transaction cost theory of new fresh agricultural products supply chain system construction [J]. Logistics Technology, 2013, (05): 99-100 + 116 .

[7] Huang Hao, Chen Xi, Li Xiaopei, Yuan Kemei, Wang Changjun. Analysis of the construction and innovation of the distribution network of fresh agricultural products -Taking the orange navel orange as an example [J]. Friends of Science, 2010, (20): 102-103.

[8] Hou Yumei, Ma Tengfei, Liu Nan. Technology of the supply chain model of fresh agricultural products in Hebei province with the leading enterprises as the core [J]. Investigation World, 2010, (10): 22-24.

[9] Tang Xiaodan, Na Ren Tuya. Construction and optimization of raw agricultural supply chain taking Inner Mongolia meat products as an example [J]. Management modernization, 2008, (02): 39-41. 